\title{
A educação do movimento dos sem-terra
}

\author{
Neusa Maria Dal Ri \\ Universidade Estadual Paulista, Faculdade de Filosofia e Ciências \\ Candido Giraldez Vieitez
}

Universidade Estadual Paulista, Faculdade de Filosofia e Ciências

\section{Introdução}

A educação no Brasil vem evoluindo segundo o diapasão de um país do terceiro mundo que se encontra em secular e interminável processo de desenvolvimento econômico. Nas últimas três décadas, o Estado brasileiro quase conseguiu universalizar a educação pública gratuita fundamental, constituída de oito anos de ensino. ${ }^{1}$ Entretanto, há ainda muitos problemas a serem resolvidos. Essa modalidade do ensino público reproduz a dicotomia característica do sistema escolar, ou seja, essa educação é destinada às classes populares e pobres, enquanto que para as classes média e alta o Estado estimula a educação privada. Acrescentemos que a educação infantil é ainda assistencial e compensatória, o ensino médio é deficitário, ${ }^{2}$ e o

${ }^{1} \mathrm{Na}$ faixa etária de 7 a 14 anos, idade em que é obrigatória a matrícula, o país atingiu o percentual de $94,9 \%$ das crianças na escola, segundo o Censo 2000 (Gois, 2002, p. A6).

${ }^{2}$ De acordo com editorial da Folha de S. Paulo de 22 de novembro de 2003, os resultados do último Exame Nacional ensino superior encontra-se privatizado em cerca de $80 \%$ das matrículas.

Vários autores, já há décadas, preocupados com a realidade social, têm formulado idéias educacionais com o propósito de incitar uma formação acadêmica que habilite a população para efetuar uma ação transformadora na sociedade, tendo como perspectiva o fortalecimento da democracia, a cidadania, a igualdade social e até mesmo o socialismo. Nesse contexto surgem formulações tais como a educação para a cidadania, a formação de consciência crítica, o cultivo dos valores humanistas e várias outras.

Nesse campo de preocupações inserem-se os esforços pedagógicos do Movimento dos Trabalhadores Rurais Sem Terra (MST). Com a ressalva de que se trata de uma práxis pedagógica que está em conso-

do Ensino Médio (ENEM) demonstram que "[...] o estudante carente que chega ao final do ciclo médio já faz parte de uma pequena elite, pois boa parte dos mais pobres abandona os estudos bem antes. No Brasil, infelizmente, a escola pública não se tem mostrado um instrumento eficiente de inclusão social"' (p. 2). 
nância com a experiência político-social e organizativa mais ampla do próprio Movimento. ${ }^{3}$ Assim, cabe ressaltar que a práxis educacional do MST é diferente das outras proposições críticas existentes.

Neste artigo tomaremos como objeto de análise o Instituto de Educação Josué de Castro (IEJC), em especial o curso de Técnico em Administração de Cooperativas (TAC). O IEJC tem como mantenedor o Instituto Técnico de Capacitação e Pesquisa da Reforma Agrária (ITERRA), que é vinculado ao MST. Tem sua sede atual no Município de Veranópolis, Rio Grande do Sul. O IEJC constitui-se em uma escola de educação média e profissional que combina

[...] objetivos de educação geral, escolarização e formação de militantes e técnicos para atuação no MST. Seu funcionamento está organizado em torno de cursos formais de nível médio, de educação profissional e de formação de professores, criados a partir de demandas apresentadas pelos diversos setores do MST. (ITERRA, 2001, p. 5)

Este trabalho apóia-se em pesquisa empírica realizada no IEJC, em novembro de 2001. Nessa ocasião, o IEJC mantinha, além do TAC, o curso de formação de professores (Curso Normal de Nível Médio), atividades de formação de curta duração como seminários, oficinas e cursos livres de qualificação profissional, e estava também iniciando o curso de nível médio sobre saúde. O Instituto tem alunos oriundos de 21 estados do país e os cursos funcionam em tempo integral, em regime de internato.

O objetivo deste texto é expor os elementos educativos principais presentes no IEJC, bem como elucidar se a sua concepção educacional, que parece ser a mesma vigente nas escolas controladas pelo MST, contém elementos educacionais de interesse para as

${ }^{3}$ A ação educativa do MST ocorre principalmente por meio da participação no Movimento. Contudo, ações educativas por meio da escola também estão sendo desenvolvidas. A esse respeito ver Caldart (2000). classes trabalhadoras em geral, do ponto de vista democrático e popular.

A concepção de educação do MST comporta vários aspectos teóricos e ideológicos, bem como diversas práticas educacionais. Para os propósitos deste artigo, no entanto, tomaremos apenas os aspectos que consideramos elementares ou básicos e sobre os quais o Movimento, num processo experimental, vai buscando erigir uma pedagogia.

Nesta reflexão sustentamos que os elementos básicos presentes na concepção educacional do IEJC estão em correspondência com a práxis econômica e com a organização política de base do MST, e que há, também, influências teóricas educacionais advindas principalmente de Pistrak, de Paulo Freire e da pedagogia da alternância.

\section{Educação para a reprodução do Movimento}

Como ocorre com outras organizações que divergem da ordem social capitalista, o MST percebe que o ensino oficial não atende às necessidades de formação dos seus membros, pois podemos dizer em relação à educação o que já se disse em relação à ideologia: na sociedade de classes, a educação dominante é a educação das classes dominantes, ainda que a ideologia pedagógica oficial apresente-se travestida na forma de conhecimentos, valores e habilidades universais.

Nesse sentido, o IEJC foi criado para atender às características e necessidades específicas do MST, dentre as quais se destacam a formação dos militantes e quadros do Movimento.

O empenho do MST em criar uma instância de educação própria é análogo ao de outras organizações coletivas de massa, como partidos e sindicatos, uma vez que compreendem que a escola burguesa, dada a sua concepção de mundo, lhes é antagônica. Contudo, a similitude entre o IEJC e as agências educacionais normalmente utilizadas por outras organizações populares para a formação de seus militantes termina aí.

$\mathrm{O}$ ensino ministrado no IEJC relaciona-se diretamente com a especificidade do militante que o Mo- 
vimento necessita. Para o Movimento, não basta que o militante tenha formação política, ainda que esta seja essencial. Paralelamente a essa qualidade, o Movimento precisa que o seu membro tenha também capacitação técnica, bem como desenvolva as aptidões necessárias à organização coletiva da vida social, à organização coletiva da produção e de outras atividades econômicas.

Esses requisitos derivam de uma característica organizacional insólita do MST no contexto das organizações populares, ou seja, o fato de que três instâncias da realidade social - a política, a econômica e a social -, que se encontram normalmente separadas nas práxis de outras organizações, no MST encontram-se organicamente reunidas.

O militante do partido não vive no partido, o associado ao sindicato não vive no sindicato, embora ambos possam vivenciar com maior ou menor intensidade suas entidades.

Os membros do MST, diversamente, encontramse articulados ao Movimento não apenas por ideologia e funções políticas, mas também pelo fato de encontrarem-se inseridos em alguma das suas estruturas organizacionais de base, que são o acampamento e o assentamento.

O acampamento é a forma primária de organização e luta no MST, pois ele ou prepara a ocupação de terra ou é organizado imediatamente após esta. O acampamento organiza as famílias, tendo em vista a realização de atos, especialmente a ocupação, que conduzam à conquista da terra. Nesse sentido, o acampamento é uma instância de luta. Entretanto, também é um meio de sobrevivência e reprodução da vida social, na medida em que origina uma comunidade que desenvolve uma sociabilidade própria e que se mantém unida, muitas vezes, por vários anos. Por essa razão, a comunidade do acampamento soluciona, dentro do seu caráter de transitoriedade, vários problemas elementares da vida social, tais como a obtenção e a gestão dos recursos necessários à sobrevivência, à educação, à saúde, entre outros.

Conquistada a terra, surge o assentamento. No assentamento, o problema da subsistência passa a ser mediado pela organização da produção agrária, o que implica imediatamente a produção de bens e a organização do trabalho.

A reforma agrária significa, em princípio, a divisão da terra em pequenos lotes de exploração familiar. Porém, o Movimento, compreendendo as dificuldades e limitações da exploração individual da terra no contexto de uma agricultura que compete num amplo mercado, tem-se esforçado para criar formas de cooperação entre os produtores. Segundo nosso juízo, a organização mais avançada, dentre essas formas, é a Cooperativa de Produção Agropecuária (CPA), ou seja, cooperativa socializada de gestão democrática ou de autogestão. As características básicas desse tipo de empreendimento são as seguintes: a inexistência do trabalho assalariado; a distribuição igualitária do excedente econômico; o trabalho coletivamente organizado; e a gestão democrática. A gestão democrática aqui é uma autogestão da cooperativa pelos próprios trabalhadores, com base em instâncias decisórias como assembléias gerais, núcleos de base, setores de produção e de serviços, e outros mecanismos de tomada de decisão pelo coletivo de associados ao empreendimento. $\mathrm{O}$ autogoverno, com a tomada de decisões coletivas e diretas, é um dos elementos que diferencia esse tipo de cooperativa, dentre tantos outros existentes.

Além da questão crucial de organizar a produção, o assentamento coloca outros desafios ao Movimento. Convém destacar dois problemas: a manutenção dos jovens no trabalho agrícola e a permanência dos assentados no MST.

Para os assentados que obtiveram a terra, a reforma agrária realizou-se e, em princípio, eles não teriam mais motivo para dar continuidade à luta. Concomitantemente, os jovens dos assentamentos sentem-se fortemente atraídos pela vida urbana, o que coloca em risco a continuidade desses empreendimentos obtidos com tantas dificuldades. Assim, em última análise, para o MST, trata-se tanto de garantir a exeqüibilidade do assentamento, quanto a de manter esses segmentos integrados ao Movimento com o propósito de que a luta pela reforma agrária possa avançar. 
Em suma, o MST distingue-se claramente de todas as demais organizações populares clássicas. Ele é um movimento de luta e, ao mesmo tempo, o demiurgo de uma economia distinta da economia burguesa dominante. É um sujeito ativo e até altissonante na luta de classes na ordem social brasileira. Mas a sua luta, diversamente do que ocorre com as demais organizações populares, dá-se também imediatamente no terreno da organização da produção. A reivindicação da reforma agrária não é apenas a reivindicação de acesso à terra, de distribuição de terra para quem não a tem e a quer, mas a exigência do direito de promover in continenti uma reorganização não-capitalista das relações de produção num segmento da economia agrária. ${ }^{4}$ Essa reorganização dá-se no âmbito interno dos assentamentos nos quais foram criadas as CPAs ou outras organizações do MST. As relações de trabalho instauradas nas CPAs diferenciam-se das relações capitalistas de trabalho porque, dentre outras razões, o trabalho assalariado é substituído pelo trabalho associado. No entanto, as CPAs continuam integrando o sistema do capital na medida em que são unidades produtoras de mercadorias e, conseqüentemente, atuam no mercado.

A opção do MST com a criação dos cursos mencionados reflete as determinantes discutidas anteriormente. O curso de formação de professores expressa a preocupação com a educação escolar das crianças nos acampamentos e assentamentos. O TAC revela a disposição do Movimento em promover formas variadas de cooperação e, em especial, a criação de cooperativas de trabalho coletivo e gestão democrática. E o curso de saúde indica uma outra área básica com a qual o Movimento tem de se preocupar, diante das insuficiências das estruturas públicas existentes.

${ }^{4}$ A reorganização das relações de produção também ocorre quando os trabalhadores fabris apropriam-se de uma empresa capitalista ou criam uma empresa própria, embora eles não estejam organizados em um movimento geral de autogestão nas empresas. A esse respeito, ver Vieitez e Dal Ri (2001).
A seguir, destacaremos as instâncias estratégicas que fazem com que a atividade de educação escolar do MST, voltada antes de tudo para seus membros ou militantes, configure-se como um processo pedagógico próprio, característico, significativamente distinto daquele que é praticado nas escolas oficiais, ou mesmo nas escolas de outras organizações populares.

\section{Estrutura e processos escolares}

\section{Os conteúdos curriculares}

Tomemos o exemplo do TAC. O currículo básico segue os referenciais da legislação. As disciplinas ministradas referem-se à formação geral e à administração de cooperativas. Dessa forma, nesse âmbito, o aspecto diferencial desse curso encontra-se em três variáveis: a história do Movimento; a impostação pedagógica dos professores; e a articulação entre os conteúdos disciplinares e a realidade dos acampamentos e assentamentos.

No trato da disciplina de história há duas características a ressaltar. A primeira refere-se a um importante espaço que é reservado ao estudo da história do próprio Movimento. E, embora o estudo da história do Movimento não ocorra apenas por meio dessa disciplina, como se verá mais adiante, não há dúvida de que ela contribui significativamente para a reprodução da identidade dos sem-terra. A segunda característica, correlata à primeira, é a preocupação de colocar à disposição dos alunos interpretações analíticas que não apenas evidenciam o papel histórico das classes subalternas, como também apresentam de forma positiva os seus valores e feitos, os quais aparecem contrapostos aos das classes dominantes. Acrescentamos que a história trabalhada não se apresenta simplesmente como o passado do Movimento ou da civilização, mas como um passado que se articula com o presente, particularmente com a realidade desse segmento social.

\footnotetext{
A diferença básica que existe é que o aluno tradicional, na minha disciplina, não consegue enxergar a história como
} 
algo que renda algum fruto na sua vida. Faz porque é obrigado. Aqui [no IEJC], até em função da própria formação de vida, uma das primeiras coisas que o Movimento trabalha com as pessoas é que elas conhecem uma história que não é a sua; é uma história que foi inventada por alguém devido a seus interesses. Então, os alunos têm esse interesse em saber. Por que tenho que glorificar o Duque de Caxias?

Eles têm um interesse pela história. É um marco diferencial aqui. A história de uma classe dominada. Tem gente que vem pra cá que já tem o segundo grau. O pessoal vem pra cá e muita gente diz que odiava a história. E vem aqui e vai até à biblioteca ler livros. Eles têm uma visão da história que os alunos normais não têm de jeito nenhum. Comparado com os alunos normais, é outro patamar. (Professor de História do TAC em entrevista aos pesquisadores, em 2001)

O IEJC quer ajudar a cultivar a memória do MST e do conjunto das lutas populares, e se sente responsável pela formação da consciência histórica de seus educandos e educadores. Isto implica em desenvolver alguns aprendizados básicos: compreender a nossa própria vida como parte da história; respeitar as lições da história; aprender a ver cada ação ou situação numa perspectiva histórica, quer dizer, em um movimento entre passado, presente e futuro, compreendêlas em suas relações com outras ações, situações, uma totalidade maior. (ITERRA, 2001, p. 17)

Diferentemente da escola oficial, que ministra conteúdos gerais, com escassa referência a realidades sociais mais específicas, o ensino no TAC busca constantemente estabelecer vínculos relacionais com a realidade do Movimento, dos assentamentos e acampamentos.

Um ex-aluno do TAC, atual membro do quadro pedagógico do IEJC, relembrando as impressões que teve ao chegar no Instituto, diz o seguinte:

Eu já era técnico em agropecuária, no Colégio da Universidade Federal de Santa Maria. [...] No curso Técnico eu achava que a gente estudava muitas coisas abstratas. Me perguntava quando isso serviria pra gente. E aí vi [no IJEC], quando comecei a discutir, algo mais concreto, que dizia mais respeito à gente. Nos primeiros cadernos, com os temas geradores. A relação escola e comunidade. Os problemas do assentamento, do acampamento. Parecia algo que a escola ia ajudar. [...] Aqui de fato a gente vai aprender uma coisa útil. [...] A mudança qualitativa da consciência das pessoas parece ser um dos pilares. Que as pessoas entendam o processo em que elas vivem. Ser capaz de identificar os amigos, os inimigos etc. Saber identificar problemas e resolver. Em qualquer nível elas poderão atuar. Ler a realidade, saber fazer isso. (Acompanhante de turma do TAC, em entrevista aos pesquisadores, em 2001)

Esse ensino, que contempla a realidade social da qual emergem os educandos, decorre das características do Movimento, bem como das influências teóricas de Paulo Freire, de Pistrak e da pedagogia da alternância. ${ }^{5}$

A terceira variável, a impostação pedagógica dos professores, está relacionada com a constituição do próprio quadro docente. Quando há necessidade de contratação, esta não ocorre por meio do mercado de trabalho. Os professores são indicados ou recomendados levando-se em conta a competência técnica e a proximidade com o MST. Trata-se de professores que são do MST ou que têm simpatia pelo Movimento.

Isso significa que, mesmo quando os assuntos tratados nas várias disciplinas nada têm a ver com postura ideológica ou política, os professores acabam por transmitir aos seus alunos valores e idéias favoráveis ao Movimento. Esta característica parece ser geral entre os professores, embora seja mais acentuada entre os docentes da área de humanas, pois, dada a natureza das disciplinas, há mais oportunidades de emissão de juízos acerca da realidade social. Do mesmo modo, dado o caráter diferenciado dos alunos e da escola, os professores também parecem apreciar e valorizar o trabalho no Instituto.

Os outros professores vêm pra cá com um objetivo: dar a ementa do curso. É fechado. Eles vêm e trabalham as ques-

\footnotetext{
${ }^{5}$ A respeito da pedagogia da alternância, ver Costa (1999).
} 
tões de Física, de Matemática. Não abrem para as questões políticas. A visão de todo mundo é que aqui é um lugar diferenciado. Eles gostam. Fazem questão de continuar. Muitas vezes largam tudo o que têm que fazer e vêm pra cá. Tem um professor de Química que não cobra nada do ITERRA, faz doutorado e vem aqui. É uma coisa que vai além da militância. E pela diversidade também, que é uma coisa muito interessante. Temos alunos aqui de 21 estados. Além das leituras normais, os alunos realizam outras. Eles têm uma literatura mínima para ler. Eu nunca li $O$ Capital inteiro. E eles, chegando ao fim do curso, muitos leram $O$ Capital. Eles vão se automotivando. Eles estão lendo os clássicos da literatura brasileira. Os alunos lêem no tempo leitura. Um menino veio e me disse: "Professor, estava vendo aqui um negócio no Guarani que fala da guerra entre os espanhóis e os árabes, e não estou contextualizando”. O que significa isso? Ele achou um negócio de história, não entendeu, e veio falar comigo. (Professor de História do TAC em entrevista aos pesquisadores, em 2001)

\section{A estrutura organizacional: as relações de produção pedagógicas}

A organização da escola não costuma ser apresentada como um fator pedagógico importante. Os atores escolares normalmente vivenciam essa organização sem maiores reflexões ou preocupações, considerando-a um meio para a realização dos objetivos pedagógicos propostos.

No entanto, a organização da escola é um importante elemento pedagógico, é um currículo que, por não fazer parte dos conteúdos programáticos explicitados, se encontra, por assim dizer, oculto.

A ação desse currículo incide sobre a formação dos educandos de diversos modos. Entretanto, dentre os seus ensinamentos, o mais importante é aquele que decorre do fato de as relações pedagógicas serem uma réplica, ainda que em clave escolar, das relações sociais fundamentais dominantes. Desse ponto de vista, a escola burguesa, uma organização burocrática, transmite aos alunos, por meio da vivência das relações escolares, a percepção e a visão de que as rela- ções burocráticas são as relações naturais e eternas da sociedade. Em uma palavra, uma das lições ministradas na escola consiste na visão de que a burocracia é a forma mais racional e eficiente de organização do trabalho.

O IEJC tem na organização escolar uma das principais dimensões que o diferencia da escola oficial. Nos aspectos pedagógicos, políticos e administrativos, inclusive orçamentário, o Instituto é gerido pelos alunos, professores e funcionários. O mecanismo básico operatório da gestão é o que se denomina no IEJC de reprodução da gestão. Isso significa que mensalmente há uma avaliação e um novo planejamento de todas as atividades.

O Instituto tem várias instâncias organizacionais nas quais participam alunos, professores e funcionários. Paralelamente a essas instâncias mistas, há organismos compostos apenas por alunos. Trata-se da auto-organização dos alunos em núcleos de base.

Essa estrutura, que apresenta várias mediações, conflui para a assembléia geral do Instituto, da qual participa toda a comunidade escolar. A assembléia geral delibera mensalmente sobre a maior parte das questões que se apresenta à escola, desde o orçamento até possíveis problemas pedagógicos.

A assembléia geral é o organismo superior de tomada de decisões do Instituto. Acima dela, com o papel de realizar a mediação entre o Instituto e a direção do MST, encontra-se a Direção Política do IEJC/ MST. Essa direção atém-se a questões estratégicas que implicam princípios e diretrizes políticas do Movimento. ${ }^{6}$

Em suma, há uma grande autonomia na gestão da escola, preservados os vínculos e diretrizes gerais que emanam do MST.

6 "No dia-a-dia, a autonomia está nos núcleos de base. O MST tem autoridade para vir aqui [IEJC], ou através da minha pessoa, e cuidar da observância dos princípios. Os educandos sabem o que o MST quer. Então, eles respeitam isso. Há um entendimento diante dos princípios" (Diretora do Instituto e membro da Direção Nacional do MST, em entrevista aos pesquisadores, em 2001). 
Ressaltamos que, embora exista uma hierarquia em relação à direção do Movimento, esse tipo de organização apresenta um grau de radicalismo democrático que se encontra em divergência com a organização burocrática da escola oficial. Na percepção dos membros do IEJC, trata-se da gestão democrática. No entanto, podemos concluir que essa organização pode também ser denominada de autogestão. ${ }^{7}$

\section{Atividades culturais e lúdicas}

O Instituto desenvolve várias atividades culturais, lúdicas e recreativas. Porém, destacaremos apenas aquela que constitui um dos elementos que diferenciam a pedagogia do IEJC. Trata-se do que no Movimento denomina-se de mística.

A realização da mística é de responsabilidade dos núcleos de base formados pelos alunos. Ela é realizada formalmente todos os dias, pela manhã, mas pode ocorrer também em várias outras situações. A mística é expressa por meio de poesias, performances, músicas, expressões corporais, palavras de ordem, símbolos do MST, entre outras.

A mística tem a finalidade de manter a identidade dos sem-terra, reviver os sentimentos das pessoas pelo Movimento e desencadear o respeito aos seus símbolos. Por meio da mística resgata-se a memória de eventos importantes para o MST e para a classe trabalhadora, rememoram-se episódios de lutas e a

${ }^{7} \mathrm{O}$ ordenamento estatutário e jurídico da cooperativa de produção de trabalho associado possibilita o exercício democrático do poder por todos os trabalhadores. Esse fato é fundamental, na medida em que essa dinâmica diferencia-se dos mecanismos representativos clássicos. No entanto, há vários intervenientes que inibem e limitam o exercício da gestão democrática. Uma delas é a oposição latente e/ou real existente entre o conjunto dos trabalhadores e os seus quadros, pois os últimos freqüentemente detêm a hegemonia nas organizações. Por essa razão, dadas as condições atuais, a gestão democrática deve ser considerada um tipo de gestão na qual os quadros tendem a ter um peso excessivo. A esse respeito, ver Vieitez e Dal Ri (2001). atuação de figuras destacadas na história. É também uma forma de ensinar às gerações mais jovens a história de lutas do Movimento, bem como afirmar os seus princípios, objetivos e ideologia.

No IEJC, a mística

\begin{abstract}
Vai muito do que o núcleo de base pensou. De manhã cedo chamamos todos os núcleos de base para ver se está faltando alguém, se está doente, e dar os avisos do dia. Aí tem uma encenação, um teatro, a motivação do dia, cantar a música. Se sair ruim, na reunião todo mundo cobra. A mística de ontem foi uma homenagem ao Zumbi. O pessoal tem que buscar, pesquisar, inventar. [...] Mística? Aprendemos com a Igreja. (Diretora do Instituto e membro da Direção Nacional do MST, em entrevista aos pesquisadores, em 2001)
\end{abstract}

O objeto da mística é sobretudo a história ou os eventos significativos da história do MST e do movimento operário e popular. Porém, a História é ministrada como disciplina científica e segundo o método inerente à sua condição. Diferentemente, a mística busca mobilizar cotidianamente as energias psíquicas da evocação, do imaginário, do simbolismo, vale dizer, do que desencadeia mais facilmente os sentimentos e a afetividade.

A escola do trabalho e o trabalho na escola

A escola na sociedade capitalista desempenha várias funções, sendo que a mais imediata para o capital é a de formar mão-de-obra para o mundo do trabalho. Entretanto, a relação entre a escola e o mundo do trabalho não é direta, encontrando-se mediada pelo mercado. ${ }^{8}$ Desse ponto de vista, o estudante é um trabalhador em potencial, ${ }^{9}$ que deverá integrar o merca-

\footnotetext{
${ }^{8}$ A esse respeito, ver Vieitez e Dal Ri (2001).

${ }^{9}$ A sociedade capitalista criou a categoria social dos estudan-
} tes. O estudante, enquanto categoria, não tem relação direta com o mundo do trabalho. Mesmo o estudante que é ao mesmo tempo um trabalhador apresenta essa característica, pois o seu estatuto como aluno não mantém relação alguma com o de trabalhador. 
do para poder realizar esse potencial. Dito de outra forma, a escola não educa diretamente para o trabalho na produção, mas para que o estudante convertase numa força de trabalho habilitada, que as organizações buscarão no mercado de trabalho, o qual é uma das categorias fundamentais da ordem social.

A realidade no IEJC já é outra. Uma das principais características das escolas do MST ou das que estão sob a sua hegemonia é o vínculo direto entre o ensino e o trabalho. E esse vínculo dá-se por meio do trabalho real, concreto.

A concepção de ensino vinculado ao trabalho não é uma novidade e nem é um método defendido e aplicado apenas pelos críticos da educação burguesa. Várias correntes de pensadores têm colocado e discutido a questão do princípio do trabalho na escola, embora com variações nos objetivos e propostas. Da mesma forma, a burguesia não apenas propôs, mas implantou, em vários momentos da história, escolas ligadas ao trabalho. Entretanto, as idéias principais que sempre estiveram alicerçando essas propostas, excetuando as de alguns autores, são, basicamente, as de que o aluno aprende mais e melhor por meio do trabalho; o aluno torna-se mais disciplinado, organizado e aprende a valorizar e a respeitar o trabalho. Ou seja, a maioria das correntes parece considerar o trabalho de uma forma abstrata, laboratorial, como uma disciplina escolar, portanto, isolada e separada do ato real de produção.

Destacamos um autor que se colocou como crítico das abordagens existentes em sua época, e que pôde elaborar uma proposta de vínculo entre a educação e o trabalho real na produção. Trata-se de Pistrak, educador russo e autor da obra Fundamentos da escola do trabalho, escrita em 1924.

O trabalho na escola, enquanto base da educação, deve estar ligado ao trabalho social, à produção real, a uma atividade concreta socialmente útil, sem o que perderia seu valor essencial, seu aspecto social, reduzindo-se, de um lado, à aquisição de algumas normas técnicas e, de outro, a procedimentos metodológicos capazes de ilustrar este ou aquele detalhe de um curso sistemático. (Pistrak, 2002, p. 38)
A importância de Pistrak, aqui, está no fato de que, ao que tudo indica, foi a esse autor que o MST recorreu, enquanto influência teórica, para pensar um dos princípios da sua pedagogia: "a educação para o trabalho e pelo trabalho" (MST, 1996, p. 15). Dessa forma, essa referência ocorre, sobretudo, porque essa é a proposta que melhor atende às necessidades do Movimento.

Que tipo de formação, na fase atual, o Movimento necessita? O Movimento precisa que os seus militantes e trabalhadores da terra aprendam a lutar, a organizar e a gerir a produção. O estudante do IEJC já era uma pessoa integrada ao trabalho antes de ir para a escola. E mesmo depois de integrar-se a ela continua sendo um trabalhador, ainda que em condições especiais, as quais garantem a sua permanência na escola.

Como é possível um estudante, em regime de internato, ser um trabalhador e continuar sendo, mesmo estando na escola? Isso ocorre por várias formas.

A primeira delas diz respeito ao que se denomina pedagogia da alternância. Os cursos do Instituto estão organizados em etapas, cada uma constituída de dois tempos: o tempo escola e o tempo comunidade. O tempo escola é o tempo no qual os alunos ficam no Instituto e desenvolvem um conjunto de atividades do curso e a participação na gestão da escola. $\mathrm{O}$ tempo comunidade é o tempo no qual os alunos retornam aos acampamentos ou assentamentos, realizando tarefas que foram delegadas pelo IEJC ou pelas instâncias do MST. Nesse tempo os alunos combinam atividades de estudo com a participação direta nas ações do Movimento, continuam ou iniciam tarefas que os levaram a fazer um curso específico e atendem às demandas de trabalho de cada local.

As comunidades do MST onde se realiza o trabalho produtivo não têm mais como objetivo absoluto a extração do excedente econômico da força de trabalho. Em decorrência, essas organizações podem substituir competição por ações solidárias e de cooperação, o que lhes permite adaptar às suas condições o estudante-trabalhador.

Um aluno do TAC, assentado e solteiro, diz o que significam essas ações solidárias. 
Planto arroz, milho, feijão, mandioca, batata-doce e abóbora. Só vendo o excedente. A maioria fica para o consumo. Eu sou ligado a uma família, então contribuo com essa família. Agora que estou estudando, não só pra mim, então a comunidade está assumindo o meu trabalho. Lá não tem cooperativa, tem associação. Não é perfeito. Onde tem cooperativa essa questão é mais bem controlada. Mas, onde tem associação ou outro coletivo também funciona. (Aluno do TAC, há um ano e meio no Instituto, coordenador de Núcleo de Base e coordenador da Coordenação dos Núcleos de Base, em entrevista aos pesquisadores, em 2001)

Em virtude do fato primário, qual seja, de todo e qualquer membro do MST ser um trabalhador, desde tenra idade, ainda que em condições especiais como a relatada, decorre que entre as escolas do Movimento e as suas unidades econômicas não pode haver a separação radical que se observa entre o universo empresarial e a escola oficial.

Como há uma ligação orgânica entre escola e trabalho, observa-se uma outra questão fundamental, que é o desaparecimento da tarefa básica que cumpre a escola em uma sociedade capitalista: a formação de mão-de-obra para o mercado de trabalho. O MST procura estabelecer um vínculo direto entre a escola e os seus empreendimentos econômicos. O aluno do TAC, por exemplo, pode, se assim o desejar, dirigir-se ao mercado de trabalho e disputar uma vaga em qualquer organização, pois a formação que recebe no IEJC o habilita para isso. Contudo, os empreendimentos econômicos do MST, notadamente as cooperativas de trabalhadores associados, não constituem um mercado de trabalho e nem interagem com este, uma vez que suprem suas necessidades de trabalho por meio de outros mecanismos. O aluno formado pelo TAC não vai à busca de um emprego, pois ele já pertence a uma comunidade de trabalho, ou poderá ser alocado em outro setor qualquer do Movimento.

Um dos objetivos é que, no tempo comunidade, ele [aluno] comece a se inserir nesse coletivo para ajudar a resolver os problemas que tem ali. Quando termina o curso, a grande maioria já é sabedora de onde vai trabalhar.

\begin{abstract}
Alguns vão para o mercado de trabalho. Mas é uma minoria. A maioria vai mesmo para os assentamentos e acampamentos. (Acompanhante de turma do TAC, em entrevista aos pesquisadores, em 2001)
\end{abstract}

Os estudantes do IEJC trabalham durante o tempo escola no qual ficam na Instituição. Eles atuam em três setores básicos: a) a manutenção e conservação da escola, o que significa o desempenho de vários tipos de trabalhos domésticos como cuidar da limpeza, lavar e passar roupa, cozinhar e organizar o refeitório coletivo; b) as unidades de produção, que aportam produtos in natura para consumo próprio ou que são colocados no mercado, gerando renda monetária; c) a gestão coletiva da escola, que é responsável por sua organização e funcionamento.

Um dos trabalhos mais importantes que os alunos realizam é a gestão da escola, a qual compartilham com professores e funcionários, como assinalado. Além dessa tarefa estratégica e primordial, os alunos ajudam a custear o Instituto, administrando e trabalhando nas unidades de produção. Uma pequena fábrica de conservas, que coloca seus produtos no mercado, além de gerar uma renda monetária permite aos alunos vivenciarem a comercialização, os processos de trabalho e a administração do negócio. Função análoga tem a padaria, que atende às necessidades de consumo da escola e também coloca no mercado local uma parte da produção. A horta fornece produtos in natura. E a creche, denominada Ciranda, cuida das crianças da comunidade escolar.

Convém ressaltar que o trabalho realizado no Instituto pelos alunos não é uma simulação laboratorial, mas trabalho real que, de algum modo, se articula com a economia. Entretanto, o seu significado é ao mesmo tempo educativo, pois uma das premissas da abordagem pedagógica do Instituto é a de ligar organicamente o ensino e o trabalho.

\section{Funções sociais da escola}

A escola capitalista desempenha várias funções sociais. Dentre elas destacam-se a preparação da força 
de trabalho para o mercado, a legitimação da ordem social por meio da ideologia e de outros mecanismos, e a transmissão de conhecimentos culturais e científicos.

No IEJC observam-se alterações significativas quanto às funções sociais que a escola desempenha. A transmissão de conhecimentos científicos, lingüísticos e culturais é realizada por meio das disciplinas, como em qualquer escola. Porém, a tônica de exposição não é a do universalismo, como ocorre na escola burguesa. Observa-se uma preocupação em explicitar os possíveis vínculos existentes entre ideologia, ciência e classes sociais, o que é mais evidente quando a organização da sociedade é o objeto de explicação. Esta questão remete-nos imediatamente à função ideológica da escola. A função de transmissão de ideologia também se encontra no Instituto. Entretanto, a sua teleologia não é a legitimação da ordem estabelecida, mas a reprodução e o fortalecimento do Movimento segundo um ponto de vista determinado de classe social.

No ensino oficial, o vínculo entre a escola e o mundo do trabalho é forte porque a escola, em sua condição de habilitadora universal da força de trabalho, constitui uma peça essencial do mecanismo de reprodução do mercado de trabalho e, por último, da extração do excedente econômico.

A relação entre ensino e universo do trabalho no Instituto é outra. A categoria de estudante tal qual se apresenta na escola oficial se desarticula. $\mathrm{O}$ aluno não está destinado a integrar o mercado de trabalho. Uma vez concluído o curso, o aluno permanece em sua comunidade de origem, na qual já é um trabalhador, ou desloca-se para um outro setor no âmbito de atuação do Movimento. Em qualquer dos casos, os critérios de alocação não estão presididos pela lei do valor e pela extração do excedente econômico, mas sim pelos requisitos políticos do Movimento, bem como as necessidades de reprodução das comunidades de trabalho.

\section{Conclusão}

Os cursos do IEJC são reconhecidos pelo MEC e atendem aos dispositivos impostos pela legislação educacional vigente. Entretanto, o Instituto introduziu nos cursos elementos pedagógicos diferenciados, concordantes com a visão educacional do MST, e que são responsáveis pelo caráter sui generis da pedagogia adotada. Esses elementos pedagógicos dizem respeito aos conteúdos disciplinares, ao modo como a escola se organiza, aos processos de ensino e aprendizagem e às funções que a escola desempenha no Movimento.

As disciplinas ministradas são as usuais para os cursos do mesmo gênero, e caracterizam a cultura, a tecnologia e a ciência contemporâneas. Contudo, um enfoque de classe, nomeadamente a dos trabalhadores do campo, contrapõe-se ao universalismo abstrato dominante na escola oficial.

Uma das mudanças introduzidas mais importantes é o modo de organização e funcionamento da escola. Um sistema de poder baseado em uma democracia direta, na autogestão ou gestão democrática partilhada por alunos, professores e funcionários, em condições de igualdade inusitada na ordem social, substitui a variante meritocrática da burocracia que domina a escola pública, ou o despotismo imediato da personificação do capital na escola privada.

A articulação entre o ensino e o trabalho real é uma outra modificação importante. A categoria de estudante, típica da escola capitalista, tende a dissolver-se, dando lugar à categoria de estudante-trabalhador. Concomitantemente, as organizações econômicas do Movimento, sobretudo os vários tipos de cooperativas, afastando-se do economicismo da empresa tradicional, passam a partilhar com a escola a responsabilidade pela educação.

Outra mudança diz respeito às funções sociais da escola. Uma das funções mais significativas da escola oficial é a habilitação da força de trabalho que compõe o mercado de trabalho capitalista. O propósito do IEJC não é habilitar os estudantes para compor o mercado, embora os formados estejam preparados para isso e possam fazê-lo. De fato, o trabalhador estudante, uma vez terminado o seu curso, geralmente retorna para trabalhar em sua comunidade. Em alguns casos o aluno formado no Instituto pode, tam- 
bém, ser alocado em outra unidade de produção que não a sua de origem, dependendo das necessidades políticas, econômicas e técnicas do Movimento. A intersecção entre a escola e as organizações econômicas não se dá pela mediação do mercado de trabalho, mas sim por meio do estabelecimento de relações diretas e orgânicas entre elas.

Alguns pensadores, como Freire e Pistrak, exercem influência na concepção pedagógica do MST. Freire insiste na necessidade da conexão entre a educação e a transformação da consciência do sujeito em consciência crítica, bem como na emancipação humana. Pistrak, criticando a utilização do trabalho na escola como simples exercício educacional, preconiza a integração do ensino com o trabalho real na produção.

A contribuição das teorias é real. Mas deve-se ter em conta que a pedagogia em questão expressa as características, as necessidades e os interesses da práxis política e econômica do MST.

Compelido a organizar a sobrevivência das famílias nos acampamentos e a produção nos assentamentos, o MST chegou a formulações organizacionais que, embora tendo como referência essas distintas instâncias, confluem em pontos estratégicos.

No acampamento, a disciplina é rígida. A tecnologia social de organização empregada é a autogestão do acampamento pelas famílias que o compõem. Essa tecnologia é uma variante radical dos parâmetros e procedimentos democráticos que historicamente diferenciam as organizações populares das organizações burguesas (Vieitez \& Dal Ri, 2000b).

Nos assentamentos, o MST viu-se rapidamente às voltas com os limites da pequena exploração agrária familiar num contexto de supremacia da grande propriedade fundiária e de economia-mundo. A proposta formulada, visando a superação das limitações da pequena exploração familiar, é a cooperação, a qual vem sendo encetada segundo patamares de organização e desenvolvimento bastante diversos. $\mathrm{Na}$ mais radical das formas de cooperação experimentadas até o presente, de alcance ainda restrito, encontra-se a cooperativa de produção de trabalho associado.
Nesse tipo de cooperativa reaparece, como um princípio de organização, a categoria de autogestão. A premissa para o funcionamento da autogestão, ou gestão democrática, segundo a variante cooperativa, apresenta as seguintes determinantes básicas: a propriedade da terra por um coletivo de trabalhadores; a supressão do trabalho assalariado; a distribuição igualitária e ou eqüitativa dos rendimentos. Resumindo, a instauração de um modo de apropriação do excedente econômico que descarta a exploração econômica e a subordinação política dos trabalhadores, pilares típicos do capitalismo. Portanto, esse tipo de organização abre espaço para a vigência de formas igualitárias de produção e de distribuição, bem como para a autogestão dos trabalhadores.

Esclarece-se, pois, a conexão existente entre a pedagogia e a prática política e econômica do MST. A autogestão pedagógica, uma categoria central, é a reedição na escola da autogestão nas organizações políticas e, em parte, nas organizações econômicas de base do Movimento. A categoria de autogestão, na medida em que expressa o controle da vida escolar pelos sujeitos imediatos da ação educativa, é demonstrativa das origens da educação de classe desenvolvida no IEJC. A liquidação do trabalho assalariado, assim como sua substituição pelo trabalho associado, assinala a razão pela qual desaparecem o mercado de trabalho e a função da escola como habilitadora da força de trabalho. A formação de organizações econômicas, cujo objetivo primordial é a reprodução da comunidade de trabalho, rompe com o economicismo, o que possibilita a articulação solidária das cooperativas com as escolas e a conjugação do ensino com o trabalho real.

A cooperativa de produção de trabalho associado representa hoje no Movimento a fronteira mais avançada de organização econômica e, num certo sentido, também política. Essa fronteira não reflete as diversas e contraditórias realidades que compõem o universo do Movimento, mas exprime uma tendência programática ou o que pode vir a converter-se numa linha real de desenvolvimento. Isto é, a pedagogia adotada pelo Instituto não exprime a realidade multi- 
facetada e controversa do conjunto formado pelas unidades econômicas do MST, mas exprime o segmento mais avançado dessa realidade.

Lopes, estudando um dos maiores assentamentos do MST, cujas cooperativas têm por base a pequena exploração privada familiar, surpreendeu-se com o comportamento conservador e o vigor do individualismo e do mercantilismo manifesto por seus integrantes, em razão do que apresenta a seguinte interpretação:

[...] o próprio MST, centrando o cooperativismo como uma de suas principais estratégias de articulação do assentamento - observando a questão a partir do caso em estudo acaba refém, como que numa armadilha, do próprio sistema que, paradoxalmente, lhe garante ampliar as lutas para além da conquista da terra. Pelo viés econômico e pela lógica produtivista que acabam sendo implementadas pela prática cooperativista, o Movimento não faria mais que deslizar e reproduzir a mesma "redução da volta ao indivíduo com a prevalência exclusiva do mercado". (Lopes, 2002, p. 324-325)

Lopes, contudo, parece considerar que na agenda cultural do Movimento, da qual faz parte a educação, há um programa mais avançado, com um potencial contra-hegemônico e de emancipação que se colocaria para além das limitações da vida econômica que ele observou:

\footnotetext{
Quando o Movimento se prescreve como sujeito coletivo a partir do indivíduo que produz vida e não exclusivamente mercadoria, parece-nos, a partir de nossas impressões no [assentamento] Ireno Alves, que alcança maiores avanços em termos de emancipação social: emerge a possibilidade de um projeto de construção de cultura, salta aos olhos o conteúdo ministrado em suas escolas [...]. Talvez seja aí o campo da ordem contra-hegemônica e efetivamente emancipatória. (idem, p. 324)
}

É pouco plausível que no MST o potencial contra-hegemônico e de emancipação possa evoluir separado das atividades econômicas, uma vez que o ca- ráter orgânico das suas várias instâncias é evidente. De qualquer modo, Lopes sugere que a pedagogia do MST é de valor geral para a emancipação dos trabalhadores, o que nos remete a uma das questões deste texto.

As proposições pedagógicas do MST podem ser aplicadas porque ele tem controle sobre o seu território e, portanto, detém a autonomia para isso. Esse território, que não deixa de ter expressão social e política, é, no entanto, excêntrico à ordem social.

Recordemos as categorias principais da pedagogia do Movimento que são o enfoque de classe, a autogestão, a conjugação do ensino com o trabalho produtivo e o estudante-trabalhador.

Essas categorias educacionais, se aplicadas na sociedade, significariam uma revolução pedagógica, o que nos coloca no campo da utopia. Seja como for, fica evidente que, ao se passar do contexto controlado pelo Movimento para o da sociedade inclusiva, passa-se da esfera de uma pedagogia que está sendo posta em prática, ainda que com restrições e sob pressão constante, para a esfera da aspiração política. A questão subseqüente é inevitável. Esses princípios são válidos quando se pensa numa ação contra-hegemônica geral e, portanto, na emancipação das classes trabalhadoras?

A pedagogia do MST está sendo elaborada e implementada em íntima conexão com as realidades sociais engendradas pelo Movimento. Se essas propostas pedagógicas não tiverem a capacidade de transcender essa realidade específica, o seu aproveitamento por outros trabalhadores fica comprometido. Porém, este não parece ser o caso, uma vez que essas proposições, independente das realidades objetivas e subjetivas que estão em sua gênese, vão ao encontro de teses que são clássicas no pensamento pedagógico crítico.

Uma parte importante da pedagogia crítica vem postulando a importância da educação para o desenvolvimento de uma consciência crítica e reflexiva nos estudantes e professores. O objeto desse trabalho pedagógico é, antes de tudo, a subjetividade dos atores educacionais. Essa subjetividade deve ser sensibilizada por meio dos conteúdos substantivos trabalha- 
dos no ato educativo, os quais implicam primordialmente conhecimentos e valores.

O que se entende por ensino crítico parece bastante impreciso no que diz respeito à avaliação sociológica da ordem social, porém esse campo da ação educativa é o mesmo no qual se coloca o MST quando assume uma educação de classe. No entanto, na pedagogia do Movimento, as proposições relativas à dimensão objetiva do ensino, ou seja, as relações de produção pedagógicas encontram-se no mesmo plano de importância da dimensão subjetiva. É nesse ponto que reside a maior originalidade da práxis educativa do MST e, possivelmente, também o seu mais importante aporte para uma concepção pedagógica geral dos trabalhadores.

Segundo essa perspectiva, a ação pedagógica deve buscar transformar estruturas, processos escolares e a própria função social da escola. A categoria que sintetiza a proposta de mudança da pedagogia do Movimento é a de gestão democrática ou de autogestão da escola por alunos, funcionários e professores.

Os educadores do MST, nos espaços que têm à sua disposição, estão implantando esse sistema organizacional a partir das primeiras quatro séries do ensino fundamental. Como ficaria essa proposição se ela fosse trasladada como consigna de luta para o ensino oficial público? Em última análise, a proposição conduziria à luta pela autogestão da escola pública por alunos, professores, funcionários, pais e outros membros da comunidade. Cairíamos com essa demanda em um extremismo? Pode ser. Em todo caso, as elites das classes dominantes já admitem a participação nas escolas públicas, o que, se por um lado significa pouco, considerando os termos legais em que está formulada, por outro mostra que o tema é socialmente significativo e que as aspirações dos trabalhadores transcendem os limites da democracia parlamentar.

Qual o potencial transformador da autogestão, na forma como o MST a está implantando em suas comunidades? Qual o potencial dessa proposição se aparecesse como bandeira de luta do movimento popular por transformações profundas no sistema escolar? Diante da derrocada do que aparecia como refe- rência para o movimento popular mundial, o socialismo real, o que parece haver no momento são mais perguntas do que respostas. Em todo caso, no processo de reflexão ora em curso, começam a aflorar algumas teses que convém destacar, dados os percalços históricos observados. Mészáros, por exemplo, em sua obra Para além do capital (2002), num esforço para tentar compreender o que houve de errado com as revoluções populares realizadas e fracassadas, afirma com toda a ênfase possível um dos princípios da autogestão: ou a emancipação dos trabalhadores será feita pelos próprios trabalhadores, ou não haverá emancipação nenhuma.

NEUSA MARIA DAL RI é professora livre-docente no Departamento de Administração e Supervisão Escolar e no Programa de Pós-Graduação em Educação da Faculdade de Filosofia e Ciências da Universidade Estadual Paulista (UNESP - Campus de Marília), e coordenadora do grupo de pesquisa Organizações e Democracia. Projeto de pesquisa atual: Educação nas organizações de trabalho associado. Publicou: DAL RI, N.M. (org.). Economia solidária: o desafio da democratização das relações de trabalho (São Paulo: Arte \& Ciência, 1999); VIEITEZ, C.G., DAL RI, N.M. Trabalho associado: cooperativas e empresas de autogestão (Rio de Janeiro: DP\&A, 2001); VIEITEZ, C.G., DAL RI, N.M. La economía social en Brasil. Revista de Economía Pública, Social y Cooperativa. Cooperativismo y economía social en América (Madrid: CIRIEC, nº 30, diciembre, p. 103-126, 1998). E-mail: neusamdr@terra.com.br

CANDIDO GIRALDEZ VIEITEZ é professor doutor assistente do Programa de Pós-Graduação em Educação na Faculdade de Filosofia e Ciências da UNESP (Campus de Marília), e coordenador do grupo de pesquisa Organizações e Democracia. Projeto de pesquisa atual: Educação nas organizações de trabalho associado. Publicou: VIEITEZ, C.G. Reforma nacional-democrática e contra-reforma: a política do PCB no coração do ABC paulista 1956-1964 (Santo André: Fundo de Cultura do Município de Santo André, 1999); VIEITEZ, C.G., DAL RI, N. M. Trabalho associado: cooperativas e empresas de autogestão (Rio de Janeiro: DP\&A, 2001); VIEITEZ, C.G., DAL RI, N.M. La economía social en Brasil. Revista de Economía Pública, Social y Cooperati- 
va. Cooperativismo y economía social en América (Madrid:

CIRIEC, no 30, diciembre,p. 103-126, 1998).E-mail: candido@ marilia.unesp.br

\section{Referências bibliográficas}

CALDART, R.S., (2000). Pedagogia do Movimento Sem Terra: escola é mais do que escola. $2^{\mathrm{a}}$ ed. Petrópolis: Vozes.

COSTA, C.M., (1999). A educação de jovens e adultos trabalhadores sem terra: a experiência do curso de magistério. Dissertação de mestrado. Marília: Universidade Estadual Paulista (UNESP).

ITERRA - Instituto Técnico de Capacitação e Pesquisa da Reforma Agrária, (2001). Instituto de Educação Josué de Castro projeto pedagógico. Cadernos do Iterra. Veranópolis, ano I, $\mathrm{n}^{\circ} 2$, maio.

GOIS, A., (2002). Escolarização aumenta no país. Folha de $S$. Paulo, São Paulo, 9 maio, Caderno Censo 2000, p. A6.

LOPES, J.M.A., (2002). O dorso da cidade: os sem-terra e a concepção de uma outra cidade. In: SANTOS, B.S. Produzir para viver: os caminhos da produção não-capitalista. Rio de Janeiro: Civilização Brasileira, p. 283- 326.

MÉSZÁROS, I., (2002). Para além do capital. São Paulo: Boitempo; Campinas: Editora da UNICAMP.

MST - Movimento dos Trabalhadores Rurais Sem Terra, (1996). Caderno de Educação, Porto Alegre, $\mathrm{n}^{\circ} 8$.

PISTRAK, M.M., (2002). Fundamentos da escola do trabalho. $2^{\mathrm{a}}$ ed. São Paulo: Expressão Popular.

VIEITEZ, C.G., DAL RI, N.M., (2000a). Educação e organizações democráticas. In: DAL RI, N.M., MARRACH, S.A., (orgs.). Desafios da educação do fim do século. Marília: UNESP, p. 11-24.

, (2001). Trabalho associado: cooperativas e empresas de autogestão. Rio de Janeiro: DP\&A.

, (2000b). Virtualidades político-sociais das organizações econômicas dos trabalhadores. Org \& Demo, Marília, v. $1, \mathrm{n}^{\mathrm{o}} 1$, p. $53-70$.

Recebido em setembro de 2003

Aprovado em janeiro de 2004 
Palavras-chave: trabalhador rural; participação; esfera pública

The contribution of the ordinary man to the construction of the public sphere: rural workers in Baturité State of Ceará

Analyses the participative experience of the ordinary man - the rural landless worker, lease-holder or tenant farmerin public spaces like municipal councils, associations of small producers and the Rural Workers' Trade Union, in Baturité, a municipality of 30,000 inhabitants in the State of Ceará. The research took as its starting point a basic question: how does the ordinary man experience politics today?

Understanding politics as transgression, dispute or the changing of positions, achieved by means of discussion and demands, and by examining the possibility of constructing a public sphere, the research followed systematically the participative experiences of two rural communities, which are characterised as State offers and as civil society conquests. The participative dynamic is established by involving conflicting movements which at times are characterised as democratic and transparent relations between State and civil society and, at others, as traditional relations based on authoritarianism and cordiality, salient features of Brazilian political culture. Although the material conquests of the associative experiences are limited, gradual approximations to a style of democratic being are experienced and these, in turn, signal the production of a legacy: the quest for citizenship and the awareness of rights.

Key-words: rural worker; participation; public sphere

Neusa Maria Dal Ri e Candido Giraldez Vieitez

\section{A educação do movimento dos sem-} terra
O Instituto de Educação Josué de Castro, que tem como mantenedor o Instituto Técnico de Capacitação e Pesquisa da Reforma Agrária e é vinculado ao movimento dos sem-terra, constituise em uma escola de educação média e profissional. O objetivo desse texto é o de expor os elementos educativos principais presentes na escola, bem como elucidar se a sua concepção educacional, que parece ser a mesma vigente nas escolas controladas pelo MST, contém elementos educacionais de interesse para as classes trabalhadoras em geral, do ponto de vista democrático e popular. A investigação revelou que o Instituto, estruturado e organizado de forma diferente daquela usualmente encontrada nas escolas oficiais, coloca em epígrafe categorias educacionais como a união do ensino com o trabalho e a gestão democrática compartilhada entre alunos, professores e funcionários.

Palavras-chave: educação; trabalho; autogestão

\section{Education in the Landless Workers'} Movement

The Josué de Castro Institute of Education, sponsored by the Technical Institute for Training and Research into the Agrarian Reform, which is associated with the landless workers' movement, provides both secondary education and technical training. The aim of this paper is to explain the principal features of this school, and to clarify whether its underlying educational premises, which seem to be similar to those extant in the schools under MST control, contain educational characteristics which are of interest to the working classes in general, from a democratic and popular point of view. The investigation showed that the Institute, whose structure and organisation differ from those commonly found in state schools, takes as its motto such educational categories as the union between education and work and democratic management processes in which students, teachers and school staff participate.

Key-words: education; work; selfmanagement

Danilo Romeu Streck

\section{O Fórum Social Mundial e a agenda} da educação popular

Realiza uma leitura do III Fórum Social Mundial, a partir da perspectiva da educação popular. Trata inicialmente dos objetivos e da dinâmica do Fórum para depois identificar temas que recomponham a agenda da educação popular. O primeiro deles refere-se à necessidade e às possibilidades de a educação popular ser pensada internacionalmente. $\mathrm{O}$ segundo trata da pluralidade de aportes e dos consequientes desafios epistemológicos e metodológicos. Por fim, são identificados alguns temas emergentes ou recorrentes, com base nas 1.286 oficinas oferecidas no Fórum.

Palavras-chave: Fórum Social Mundial; educação popular

The World Social Forum and the agenda for popular education.

This article presents a reading of the III World Social Forum, based on a popular education perspective. It deals initially with the goals and the dynamic of the Forum and then identifies themes which restructure the agenda for popular education. The first of these refers to the need and the possibility of popular education being discussed internationally. The second deals with the plurality of contributions and the consequent epistemological and methodological challenges. Finally some of the emerging or recurrent themes are identified based on the 1,286 workshops offered during the Forum. Key-words: World Social Forum; popular education 